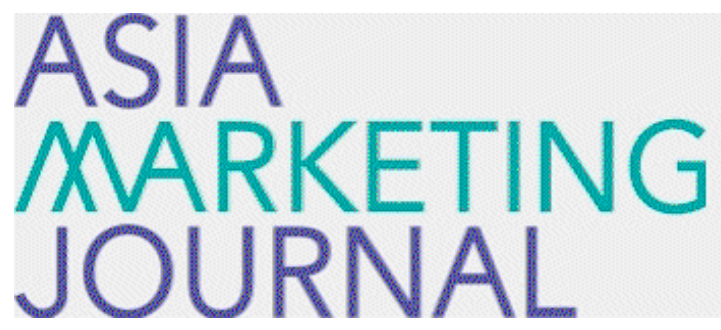

ASIA MARKETING JOURNAL

Volume 23 | Issue 3

Article 4

November 2021

\title{
Who Makes You More Disappointed? The Effect of Avatar Presentation, Company Market Status, and Agent Identity on Customers' Perceived Service Quality and Satisfaction of Online Chatting Services
}

\author{
Sangwoo Park \\ Institute for K-Digital Platform, Korea Polytechnic University, South Korea \\ Woo Jin Choi \\ College of Business Administration, the University of Seoul, South Korea \\ Dongwoo Shin \\ College of Business Administration, the University of Seoul, South Korea, dshin@uos.ac.kr
}
Follow this and additional works at: https://amj.kma.re.kr/journal
Part of the Marketing Commons

\footnotetext{
Recommended Citation

Park, Sangwoo; Choi, Woo Jin; and Shin, Dongwoo (2021) "Who Makes You More Disappointed? The Effect of Avatar Presentation, Company Market Status, and Agent Identity on Customers' Perceived Service Quality and Satisfaction of Online Chatting Services," Asia Marketing Journal: Vol. 23 : Iss. 3 , Article 4.

Available at: https://doi.org/10.53728/2765-6500.1577
}

This Article is brought to you for free and open access by Asia Marketing Journal. It has been accepted for inclusion in Asia Marketing Journal by an authorized editor of Asia Marketing Journal. 


\title{
Who Makes You More Disappointed? The Effect of Avatar Presentation, Company Market Status, and Agent Identity on Customers' Perceived Service Quality and Satisfaction of Online Chatting Services
}

\author{
Sangwoo Park ${ }^{\mathrm{a}}$, Woo Jin Choi ${ }^{\mathrm{b}}$, Dongwoo Shin ${ }^{\mathrm{b}, *}$

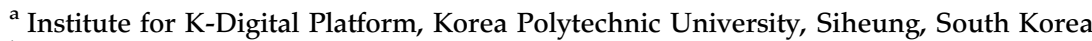 \\ ${ }^{\mathrm{b}}$ College of Business Administration, The University of Seoul, Seoul, South Korea
}

\begin{abstract}
Recent advances in interactive communication have allowed companies to introduce new digital technologies to differentiate their online customer chatting services, allowing companies to leverage both human and AI agents in their chatting services. In addition, the presentation of chatting agents is also varied including human pictures, human image, and so on. However, little is known about how these changes in online chatting service affect customer responses. To answer this call, the current research examines the effects of avatar presentation, company market status, and agent identity on customers' perception of service quality and satisfaction in the context of minor service failure that customers encounter through online chatting services. The results of two studies show that customers perceive better service quality and demonstrate lower satisfaction if served by an artificial intelligence [AI] agent (vs. a human-agent), represented by a human picture (vs. a human image). However, this pattern was found only for a company with high marketstatus, not for a company with low market-status. These results will help marketing practitioners strategically design their chatting service environments according to the nature of services they offer.
\end{abstract}

Keywords: Chatbot, Online customer agent, Avatar, Company market status, AI

\section{Introduction}

$\mathrm{O}$ nline chatting services are pervasive in many industries. Traditionally human customer representatives have serving customers in online chatting service; however, recent technological advances allow companies to utilize both human agents and AI chatbots in their online chatting services. While these two different types agents are serving customers, the presentation of these agents also vary. That is, companies vary in whom they use as their chatting agents (i.e., agent identity) and how they present those agents (i.e., avatar presentation) over online chatting tools to the consumer (see Fig. 1). For example, Amtrak presents an AI agent with a human picture; Saks Fifth Avenue presents a human service representative with the first name of the agent; Macy's uses an AI agent with its brand logo; RareCarat.com uses an AI agent with a human image. Then, how would the agent identity along with avatar presentation affect customers' service experience? Answers to those questions are important for marketing practitioners because they provide valuable information for shaping effective online chatting environments. Therefore, this research aims to understand how the presentation of the agent and a chatting agent's identity (AI vs. human) may influence customers' evaluations of online chatting services.

In so doing, we also take into account the role of the market status of a company (i.e., low vs. high) in the effect of avatar presentation on customer evaluation of the online chatting service. Research shows that people expect high quality services from

Received 16 June 2021; accepted 18 October 2021.

Available online 14 November 2021

* Corresponding author.

E-mail addresses: swpark@kpu.ac.kr (S. Park), wjchoi@uos.ac.kr (W.J. Choi), dshin@uos.ac.kr (D. Shin). 

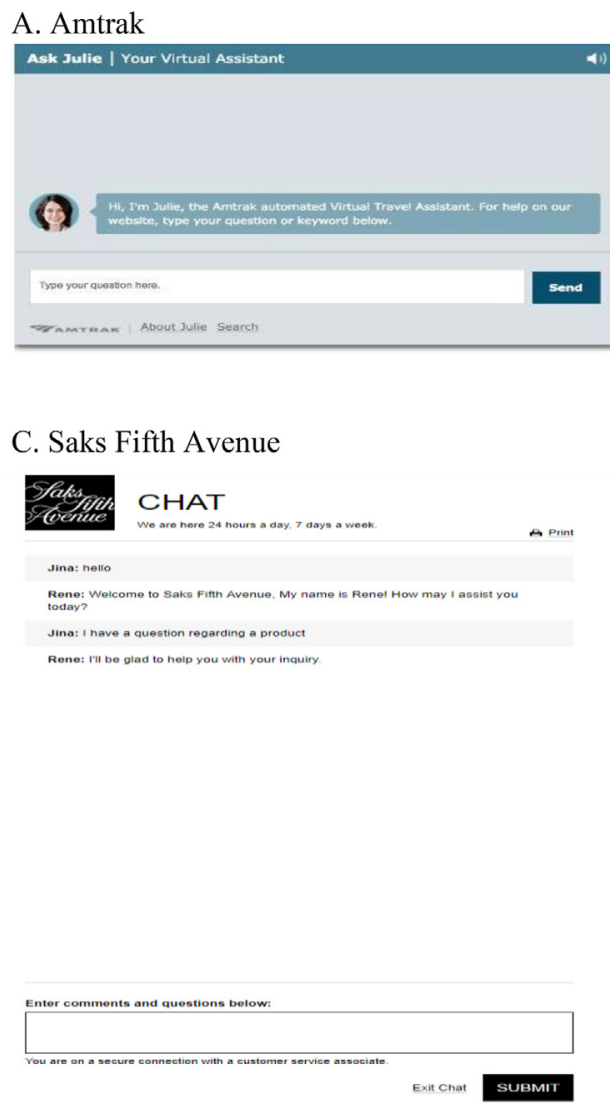

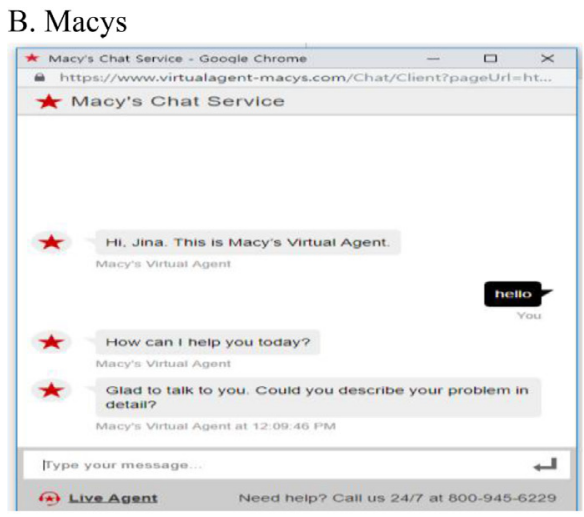

D. RareCarat.com

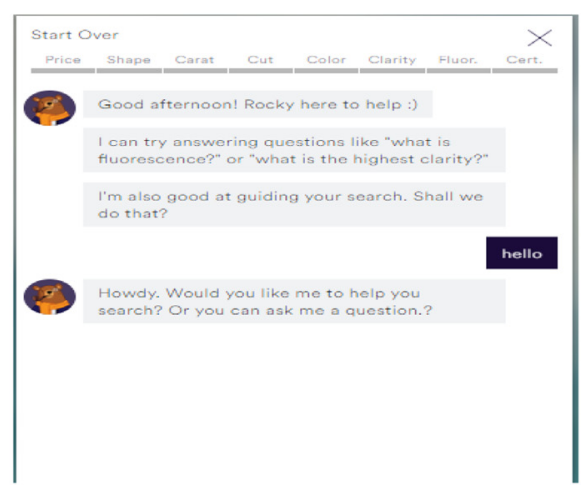

Fig. 1. Examples of presentations of customer representatives.

high market-status companies (Caminal and Vives 1996; Hellofs and Jacobson 1999) and tend to perceive highly anthropomorphized avatars as behaving in ways that are more socially appropriate and responsive (Bailenson et al. 2003). However, previous studies also show that these positive customer expectations of highly anthropomorphized avatars backfire if the avatars fail to meet the customers' expectations (Nowak and Biocca 2003; Nowak 2004). To the extent that consumers perceive online chatting services relatively newer compared to traditional customer point of contracts such as voice calls or interpersonal customer service, customers may feel less confident regarding the outcome of online services. A recent survey result done by Arm Treasure Data in 2019 indicates that $73 \%$ of respondents have had a frustrating experience in which electronic systems failed to connect them to the correct department or customer service representative. Then, it is plausible that customers' expectations regarding the quality of online chatting services would differ depending on the market status of companies due to the different levels of technologies applied to chatting services. Customers would have greater expectations for companies with high market-status compared to those with low market-status because they would infer that those with high market-status would have more advanced technologies in the chatting services. However, as stated earlier, when high market-status companies fail to serve their customers successfully in online chatting, this high expectation would induce more negative customer responses. Further, the type of avatar presentation will moderate this effect such that customers may respond more negatively if the agents are presented by highly anthropomorphized avatars, as compared to less anthropomorphized avatars. However, compared to high market-share companies, in low market-share companies, customers' expectation of online chatting services might not be as high. As a result, there would not be a significant difference in customer responses regardless of the level of avatar anthropomorphism.

To provide deeper managerial and theoretical insights, we further explore how the identity of the chatting agent reshapes the aforementioned interaction effect. Research shows that people experience a higher level of social influence (e.g., personal closeness) when they recognize that their communication partners are humans, rather than virtual entities (Bailenson et al. 2003). We propose that when customers know that their communication 
partner is a human agent, they would feel more connected and reflect company's market status more. The socially rich characteristics of a human agent may amplify the interaction effect between avatar presentation and company market status while the artificial nature of an AI agent may mitigate the interaction effect.

This research makes several theoretical contributions. Most importantly, the work adds new elements to the growing knowledge in the field of computer-mediated communications (CMC), shedding light on how to construct more effective online chatting environments. Specifically, our theorizing includes two factors that stem from recent technological advances in interpersonal communications avatar presentation and agent identity. Considering that there have been calls for further research in technology-empowered frontline interactions (Marinova et al. 2017), we believe the current research significantly contributes to this stream of literature. In doing so, we also contribute to the literature on service failure by focusing on the new business environment - online chatting service and AI agents. Managerially, we offer meaningful and easily implementable advice that will enable companies to recognize their nature and customize their avatar presentations accordingly.

\section{Conceptual background}

\subsection{Avatars as online social players}

An avatar can be defined as "computer generated visual representations of people or bots" (p. 153, Nowak and Rauh 2005) or "a pictorial representation of a human in a chat environment" (Bahorsky, Gaber and Mason 1998, p.8). In recent CMC research, there has been extensive investigation into the role of avatars online, including the impacts of avatars' characteristics on the communication process (Kang and Watt 2013; Nowak 2015; Wang et al. 2016) and consumer shopping behavior (Holzwarth, Janiszewski and Neumann 2006; Keeling, McGoldrick and Beaty 2010; Moon et al. 2013), as well as the effect of customer avatars' characteristics on customer attitudes towards brands (Aguirre-Rodriguez, Bóveda-Lambie and Miniard 2015; Suh, Kim and Shu 2011). Most relevant to our study is the literature concerning a company's avatar, where researchers focused on an avatar's role as a company representative and a social symbol in the interactions with customers (McGoldrick, Keeling and Beatty 2008). Online stores inherently lack social aspects due to their highly artificial environments; however, avatars could project diffident spectrums of social signals to online stores and thus generate socially adequate communication environments to customers (Holzwarth, Janiszewski and Neumann 2006; Nowak and Fox 2018).

Extant research suggests that people react to avatars in a similar fashion to the way they react to physical humans offline (Nowak, Hamilton and Hammond 2009; Moon 2000, 2003). An avatar's anthropomorphism, which refers to the extent to which an avatar is perceived to have human traits or qualities such as mental abilities, cognitions, intentions and emotions, or behavior (Nowak and Fox 2018), can range from a relatively non-human to a highly human appearance (McGloin, Nowak and Watt 2014). In general, people usually feel a stronger connection to an avatar with more human features (Sheehan and Sosna 1991), resulting in greater favorability (Gong 2008) and perceptions of realism, homophily, and credibility (Hamilton and Nowak 2010; Nowak, Hamilton and Hammond 2009). Highly anthropomorphized avatars also lead to greater involvement, social presence, and communication satisfaction (Bailenson et al. 2006; Kang and Watt 2013; Nowak and Fox 2018). For example, Hamilton and Nowak (2010) examined how the changes in anthropomorphic intensity (i.e., the extent to which an avatar is human-like) of an avatar affect the avatar's credibility. They showed that the highly anthropomorphic avatar generate higher competence and trustworthiness, and also have higher chance of being selected as a customer's personal avatar. In addition, Kang and Watt (2013)'s study demonstrated that less anthropomorphized avatars tend to result in lower satisfaction regarding communication.

Taken together, past research in the CMC has consistently suggested that customers are more likely to respond positively to more anthropomorphized avatars compared to less human-like ones. However, some of the contextual variables in online chatting environments may generate somewhat different directional patterns with respect to the effect of anthropomorphic intensity. In the current research, we propose that the market status of a company as such a moderating variable that will alter the relationship between anthropomorphic level (i.e., avatar presentation) and communication effectiveness. In our theorizing, we limit our discussion in the service failure situation. It has been well-known that customers are more sensitive to negative outcomes than positive outcomes due to loss aversion (Sharma, Park and Nicolau 2020). Thus, customers are more likely to contact customer services when their requests are not met compared to when their requests are successfully served. In 
addition, customers' responses to companies could differ when they receive satisfactory vs. unsatisfactory services (Han and Lee 2015; Kim and Yi 2016). Therefore, to simplify our theorizing, we develop our hypotheses assuming service failure situations.

\subsection{Avatar presentation and company market status}

A few studies (e.g., Lee and Park 2011; Triberti et al. 2017) examining the effect of social cues in virtual environments have demonstrated that changing an avatar's appearance can generate different social expectations. Our main premise of this research is that avatar presentation interacts with other contextual variables (e.g., a company's market status) in online chatting environment and shapes customers' expectations about the quality of service encounter.

A company's relative market status often generates signals to customers. Consumers perceive a firm with high market share provide high quality products (Caminal and Vives 1996; Hellofs and Jacobson 1999), so customers would expect better services from a company with higher market status. Further, more anthropomorphized avatars are believed to be intelligent and socially acceptable (Bailenson et al. 2005; Nowak, Hamilton and Hammond 2009; Nowak and Fox 2018) and create closer emotional connections with the company in people's mind (Araujo 2018). Consequently, a consumer conversing with a highly anthropomorphized avatar that represents a company with higher market status would develop greater expectations for satisfactory service. However, such positive perceptions can make customers more disappointed when their expectations are not met (Nowak and Biocca 2003; Nowak 2004). On the other hand, when a customer is conversing with less anthropomorphized avatar that represents a high market status would generate lower expectations and show a relatively more positive perception of service quality and higher customer satisfaction. A recent customer survey reveals that $86 \%$ of American consumers prefer to interact with a human agent vs. an AI agent (Press 2019); considering that the online chatting service is still in the early stage, it is quite plausible that consumers' expectations of service quality of online chatting services would differ depending on the market status of companies because they might infer that companies with low market status would not have enough technologies to successfully handle their requests. Therefore, we predict that, for a company with high market status, customers will perceive lower service quality and show lower customer satisfaction when a highly anthropomorphized avatar is used in service failure situation.

However, for a company with low market status, customers' expectations of online chatting services are not as high, mitigating the effect of avatar presentation. Therefore, we predict the two-way interaction between avatar presentation and company market status as below:

H1: The effect of avatar presentation will be moderated by company market status. Specifically, for a high market status company, the difference between in avatar presentation will be significant, such that customers will (a) perceive better service quality and (b) be more satisfied with the chatting service when the avatars are less anthropomorphized. However, for a low market status company, the difference in avatar presentation will not be significant.

In addition, as an underlying process, we propose that customers' perception of service quality and satisfaction with the online chatting experience will be driven by perceived competence and trustworthiness of the avatar agent. Prior research in the CMC literature has acknowledged that an avatar's characteristics influence how it is evaluated, and that an avatar's perceived competence and trustworthiness are important determinants of communication satisfaction (DeWester et al. 2009; Nowak, Hamilton and Hammond 2009). For example, DeWester et al. (2009) showed that the gender of the avatar affects how customers perceive its competence, and, in turn, influences its perceived trustworthiness. Hamilton and Nowak (2010) also demonstrated the path of the evaluation process that avatar's anthropomorphic intensity affects perceived competence of the avatar and perceived trustworthiness of the avatar and this in turn influences avatar choice. Therefore, we predict the mediating role of competence and trustworthiness of avatars as follows:

H2-1: The proposed two-way interaction effect between avatar presentation and company market status on service quality will be serially mediated by (a) perceived competence and (b) perceived trustworthiness of an avatar.

H2-2: The proposed two-way interaction effect between avatar presentation and company market status on customer satisfaction will be serially mediated by (a) perceived competence and (b) perceived trustworthiness of an avatar. 


\subsection{The role of agent identity}

The CMC literature (e.g., Fox et al. 2015) suggests that people react differently depending on the identity of the conversing agent (i.e., AI vs. human). That is, customers' mere perception that their communication partner is an AI (or human) agent can influence their perception of the conversations. In general, humancontrolled agents are more influential than computercontrolled agents (Blascovich et al. 2002; Nowak and Biocca 2003). People perceive higher levels of social presence, defined as "the extent to which others appeal to be real," when their communication partner is known to be a human, rather than a computer (Swinth and Blascovich 2002, p.7). A recent study by Choi et al. (2019) investigated the effectiveness of language styles (literal vs. figurative) on agent type by distinguishing human, robot, and kiosk, and found that consumers respond more favorably to human agents who use literal (vs. figurative) language. Another stream of research demonstrates that people tend to feel more engaged when playing a game with a humancontrolled opponent, versus computer controlled one, and to experience higher physiological arousal, as well as more fun, excitement and engagement (Mandryk et al. 2006; Weibel et al. 2008). More recently, Han et al. (2021) demonstrate that consumers' political identity influences their attitudes towards AI such that the more conservative consumers' political identities are, the less likely they would be favorable to AI.

In the context of service failure, however, such emotional engagement with a human agent may produce rather negative responses from customers. Therefore, we hypothesize that when customers are interacting with human customer agents, they will immerse themselves more in the conversation and, depending on the level of avatar presentation and company market status, show distinctive responses following the interaction pattern proposed in H1. On the other hand, customers conversing with AI agents will feel little emotional connection to these non-human actors and experience less adverse responses from service failure. Such a lower level of emotional engagement may mitigate the interaction effect and generate less clear results. Therefore, we propose that agent identity (A.I. or human) will moderate the interaction effect between avatar presentation and company market status in the following fashion:

H3: The proposed two-way interaction effect between avatar presentation and company market status on customer satisfaction will be significant only for a human agent, but not for an AI agent.

\section{Study 1}

Study 1 tested H1 that the effect of avatar presentation will be moderated by company market status (company status, hereafter). Since many of the previous studies have utilized human images and human pictures in order to differentiate the degree of anthropomorphization of avatars (e.g., Kang and Watt 2013; Nowak, Hamilton and Hammond 2009; Wood et al. 2005), a human image and a human picture were chosen to represent relatively lower and higher levels of avatar presentation, respectively. To verify the effectiveness of our manipulation, we conducted a pretest through Amazon Mechanical Turk (MTurk). Participants $(\mathrm{N}=82)$ were asked to imagine that they were in an online chat with a customer service representative for a hypothetical shoes retailer. Participants were randomly assigned to a chatting window with either a human image or a human picture representing the agent. Participants were asked whether the human image avatar or the human picture avatar looked like a human. The results confirmed that the levels of anthropomorphization differed between the human image avatar and the human picture avatar $\left(M_{\text {human image }}=3.53<M_{\text {human picture }}=5.02 ; \mathrm{F}\right.$ $(1,80)=46.02, p<.01)$.

\subsection{Design, procedure, and variables}

We employed a 2 (avatar presentation: human image vs. human picture) $X 2$ (company status: high vs. low) between-subjects design. A total of 91 participants $\left(54.9 \%\right.$ males; $\left.M_{\text {age }}=34.9\right)$ participants were recruited from MTurk. Participants were asked to complete the two parts of study. First, a hypothetical shoe retailer, HyperShoes.com, was introduced and company status was manipulated through different levels of market share and online reputation. Specifically, in a high status condition, the company appeared to have $90 \%$ of market share. With many followers, HyperShoes.com gave the impression of being influential in social media as well. In the low status condition, the company appeared to have $10 \%$ of market share, and seemed not influential in the social network, having only a few followers. In the scenario, participants were contacting consumer service about delivery service problems. They were presented with a hypothetical conversation with an online customer representative (see Appendix). The agent was represented by either a picture of a human or a human image. Then participants were asked to evaluate the representative's competence and trustworthiness. They also noted the perceived service quality and their degree 
of satisfaction with the chatting service. All measures used are summarized in Table 1.

\subsection{Results}

\subsubsection{Manipulation check}

To check whether company status was manipulated as intended, an independent-samples t-test was run. The results show that those in the high status condition $\left(M_{\text {high }}=6.00\right)$ felt the company was a market-leading seller compared to those in the low status condition $\left(M_{\text {low }}=2.50 ; \mathrm{t}(89)=12.392\right.$, $p<.001)$. Thus, the company status manipulation was successful.

\subsubsection{Perceived service quality and satisfaction}

An ANOVA with the average perceived service quality as the dependent variable and avatar presentation and company status as the predictors yielded a significant interaction $(\mathrm{F}(1,88)=4.73$, $p<.05, \eta 2=.05$; see Fig. 2A). No other effect was significant. Follow-up contrasts revealed that the effect of avatar presentation was not significant in the low company status condition $(p>.20)$, but marginally significant in the high company status condition $(p=.07)$. In addition, the effect of company status was not significant in the human picture condition $(p>.25)$, but marginally significant in the human image condition $(p=.05)$. In addition, an ANOVA with the average satisfaction as the dependent variable also confirmed a marginally significant interaction $(\mathrm{F}(1,88)=3.970, p=.05$, $\eta 2=.04$; see Fig. $2 B$ ). No other effect was significant. Follow-up contrasts revealed that the effect of avatar presentation was not significant in the low company status condition $(p>.70)$, but marginally significant in the high company status condition $(p=.01)$. In addition, the effect of company status was not significant in the human picture condition $(p>.55)$, but significant in the human image condition $(p<.05)$. Together, these findings provide support for $\mathrm{H} 1$.

\subsubsection{Mediation analysis}

To examine the proposed causal chain specified in H2-1, we conducted a serial multiple mediator analysis (Hayes 2017). The objective of the analysis was to examine whether the conditional indirect effect of the independent variable (avatar presentation $X$

Table 1. Measures used in studies 1 and 2.

\begin{tabular}{|c|c|c|}
\hline Variables & Measurement items & Cronbach's Alpha \\
\hline $\begin{array}{l}\text { Representative's Competence (Goog } \\
\text { 2008) }\end{array}$ & $\begin{array}{l}\text { How do you think about the customer representative of } \\
\text { Hyper Shoes? (Semantic Differential 7-points scales) } \\
\text { Unknowledgeable - Knowledgeable } \\
\text { Inexpert - Expert }\end{array}$ & $\begin{array}{l}\text { Study 1: } \mathrm{r}=.820(p<.001) \\
\text { Study } 2: \mathrm{r}=.814(p<.001)\end{array}$ \\
\hline $\begin{array}{l}\text { Representative's Trustworthiness } \\
\text { (Wheeless and Grotz 1977) }\end{array}$ & $\begin{array}{l}\text { How do you think about the customer representative of } \\
\text { Hyper Shoes? (Semantic Differential 7-points scales) } \\
\text { Unreliable - Reliable } \\
\text { Insincere - Sincere } \\
\text { Dishonest - Honest } \\
\text { Distrustful of agency - Trustful of agency } \\
\text { Inconsiderate - Considerate } \\
\text { Divulging - Confidential } \\
\text { Deceitful - Not deceitful } \\
\text { Disrespectful - respectful }\end{array}$ & $\begin{array}{l}\text { Study 1: } \alpha=.872 \\
\text { Study } 2: \alpha=.931\end{array}$ \\
\hline $\begin{array}{l}\text { Service Quality (Brady and Joseph } \\
\text { Cronin 2001) }\end{array}$ & $\begin{array}{l}\text { In terms of the outcome you received from the chatting } \\
\text { service, indicate your thoughts regarding the followings } \\
(1=\text { Strongly Disagree; } 7=\text { Strongly Agree): } \\
\text { When I leave the HyperShoes's chatting service, I usually } \\
\text { feel that I had a good experience. } \\
\text { I believe the HyperShoes's chatting service, tries to give me } \\
\text { a good experience. } \\
\text { I believe the HyperShoes's chatting service, knows the type } \\
\text { of experience its customers want. }\end{array}$ & $\begin{array}{l}\text { Study 1: } \alpha=.941 \\
\text { Study 2: } \alpha=.938\end{array}$ \\
\hline $\begin{array}{l}\text { Service Satisfaction (Maxham and } \\
\text { Netemeyer 2002) }\end{array}$ & $\begin{array}{l}\text { Please evaluate your overall chatting experience based on } \\
\text { your chatting experience }(1=\text { Strongly Disagree; } \\
7=\text { Strongly Agree): } \\
\text { In my opinion Hyper Shoes provided a satisfactory resolu- } \\
\text { tion to my request on this particular occasion. } \\
\text { I am not satisfied with Hyper Shoes's handling of this } \\
\text { particular request, and regarding this particular event.(R) } \\
\text { I am satisfied with Hyper Shoes. }\end{array}$ & $\begin{array}{l}\text { Study 1: } \alpha=.791 \\
\text { Study } 2: \alpha=.862\end{array}$ \\
\hline
\end{tabular}



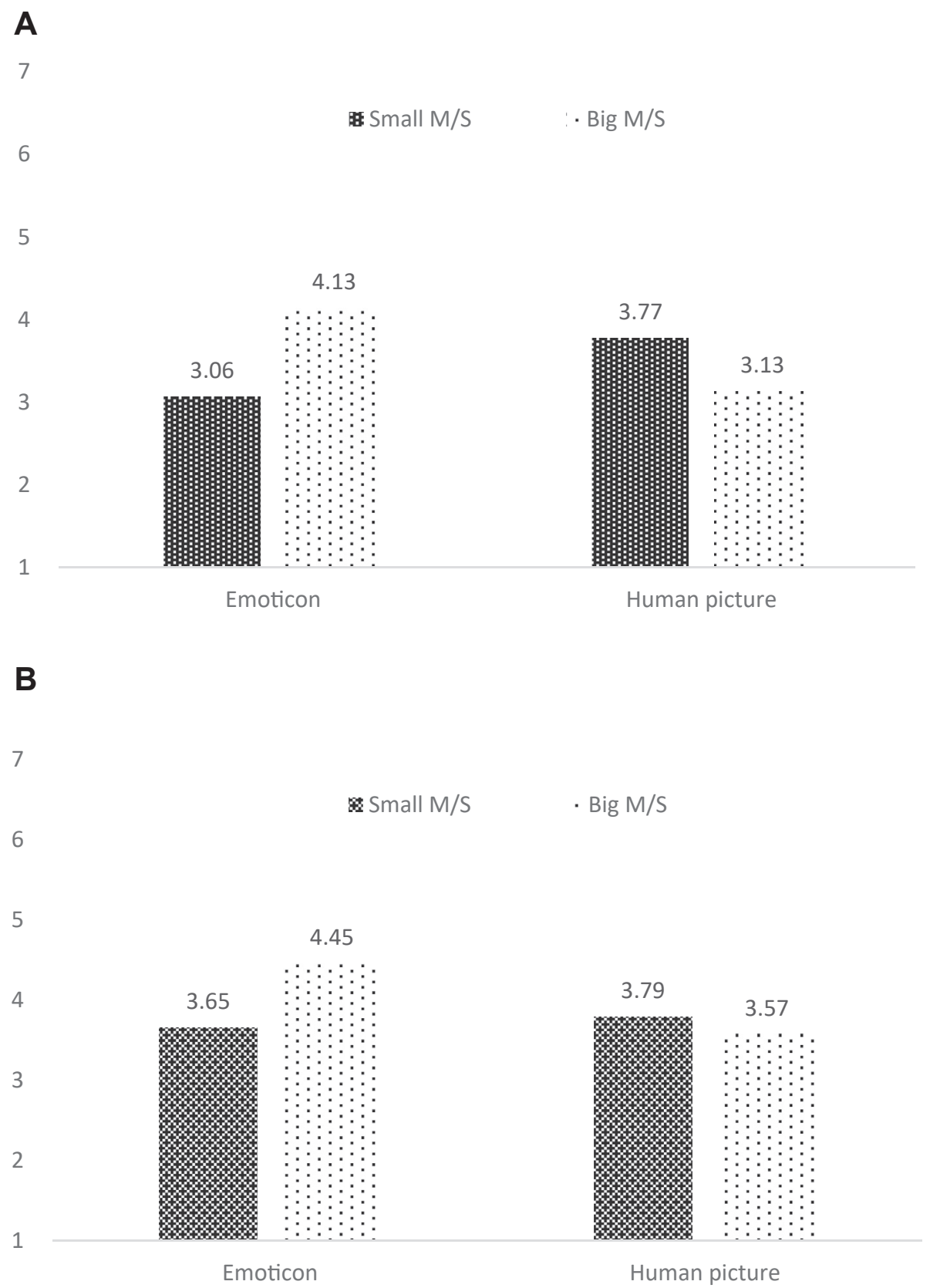

Fig. 2. A. Perceived service quality (study 1). B. Customer satisfaction (study 1).

company status) on the dependent variable (perceived service quality) followed the mediation chain through mediator 1 (competence) and mediator 2 (trustworthiness). A bootstrapping analysis with 5000 resamples was administered to examine this mediation chain using PRCESS Model 6 (Hayes 2017). We observed a significant indirect effect through the predicted causal chain: avatar presentation X company status $\rightarrow$ competence $\rightarrow$ trustworthiness $\rightarrow$ perceived service quality (95\% C.I.: $-1.6172,-.0326)$, supporting $\mathrm{H} 2-1$. Another serial mediator analysis (Hayes 2017) to test H2-2 was conducted with customer satisfaction as the dependent variables. The results confirmed a significant indirect effect through the proposed causal chain (95\% C.I.: $-1.2935,-.0156)$.

\subsubsection{Discussion}

The results of study 1 supported $\mathrm{H} 1$ and $\mathrm{H} 2$. When served by the agent with the human image, rather than one with the human picture, customers perceived greater competence and trustworthiness 
of the agent, leading to a perception of superior service quality and greater customer satisfaction. These findings suggest that, contrary to conventional wisdom, more anthropomorphized avatars backfire in service failure context; if a company with a high market status cannot meet its customers' expectations, then it would be better to use a less anthropomorphized avatar, as evidenced in Study 1.

\section{Study 2}

\subsection{Design, procedure, and variables}

The main objective of study 2 was to examine H3, which predicts the three-way interaction among avatar presentation, company status, and agent identity. We also sought to replicate the findings of study 1 . To this end, a 2 (avatar presentation: human image vs. human picture) $X 2$ (company status: high vs. low) X 2 (agent identity: AI vs. human) betweensubjects design was used. A total of 154 participants $\left(55.2 \%\right.$ males; $\left.M_{\text {age }}=34.9\right)$ participants were recruited from MTurk. The structure of Study 2 was similar to that of Study 1. First, as in Study 1, participants were told about a hypothetical shoe retailer, HyperShoes.com. The information about the company was provided according to the randomly assigned condition, that is, high or low company status condition. They were asked to imagine that they had bought a pair of sneakers from Hypershoes.com and they were chatting with an online customer representative because of a delivery issue. However, in Study 2, they were informed that the identity of customer representative was either an AI or human. Next, we administered the same measures as in Study 1 .

\subsection{Results}

\subsubsection{Manipulation check}

An independent-samples t-test demonstrated that those in the high company status condition $\left(M_{\text {high }}=6.35\right)$ felt the company was a market-leading seller compared to those in the low company status share condition $\left(M_{\text {low }}=2.88 ; t(152)=16.842\right.$, $p<.001)$, displaying successful company status manipulation.

\subsubsection{Perceived service quality and satisfaction}

As did in study 1, an ANOVA with the average perceived service quality as the dependent variable and agent identity, avatar presentation and company status as the predictors yielded a significant three-way interaction $(\mathrm{F}(1,146)=4.61, p<.05$, $\eta 2=.03$; see Fig. 3A). No other effect was significant.
Follow-up analyses showed that the interaction effect between avatar presentation and company status was significant only in the human agent condition $(\mathrm{F}(1,67)=3.75, p=.05, \eta 2=.05)$, but not in the AI agent condition $(p>.29)$. Furthermore, for those in the human agent condition, planned contrasts revealed that the effect of avatar presentation was not significant in the low company status condition $(p>.70)$, but marginally significant in the high company status condition $(p=.05)$. In addition, an ANOVA with the average service satisfaction as the dependent variable and agent identity, avatar presentation and company status as the predictors confirmed a significant three-way interaction $(\mathrm{F}(1,146)=4.20, p<.05, \eta 2=.02$; see Fig. $3 \mathrm{~B})$. No other effect was significant. Additional analyses show that the interaction effect between avatar presentation and company status was significant only in the human agent condition $(\mathrm{F}(1,67)=4.855$, $p<.03, \eta 2=.06)$, but not in the AI agent condition $(p>.54)$. Furthermore, for those in the human agent condition, planned contrasts revealed that the effect of avatar presentation was not significant in the low company status condition $(p>.18)$, but marginally significant in the high company status condition $(p=.08)$. Further, the effect of company status was not significant in the human picture condition $(p>.41)$, but significant in the human image condition $(p<.05)$. Together, these findings provide support for $\mathrm{H} 3$.

\subsubsection{Mediation analysis}

To further test the underlying process as in study 1, we ran two serial mediation models (Hayes 2017, Process Model 6). To examine the proposed causal chain specified in $\mathrm{H} 2-1$, we conducted a serial multiple mediator analysis (Hayes 2017). Bootstrapping analysis with 5000 resamples excluded zero for the proposed indirect path from avatar presentation $X$ company status $X$ agent identity first through competence then through trustworthiness to perceived service quality $(95 \%$ C.I.: -2.4331 , -.3835 ), thus supporting $\mathrm{H} 2-1$. In the second mediation model, the dependent variable was customer satisfaction. Bootstrapping analysis with 5000 resamples excluded zero for the proposed indirect path from avatar presentation $X$ company status $X$ agent identity, first through competence, then through trustworthiness to customer satisfaction (95\% C.I.: $-1.0906,-.1470)$, thus further supporting $\mathrm{H} 2-2$.

\subsubsection{Discussion}

The results of study 2 replicate those of study 1 , demonstrating that when customers were chatting 
[1. AI condition]

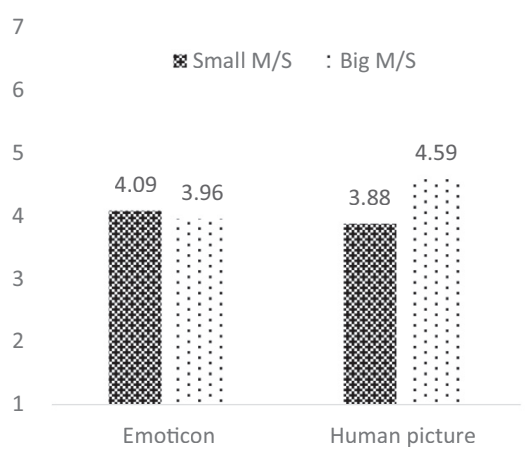

[1. AI condition]

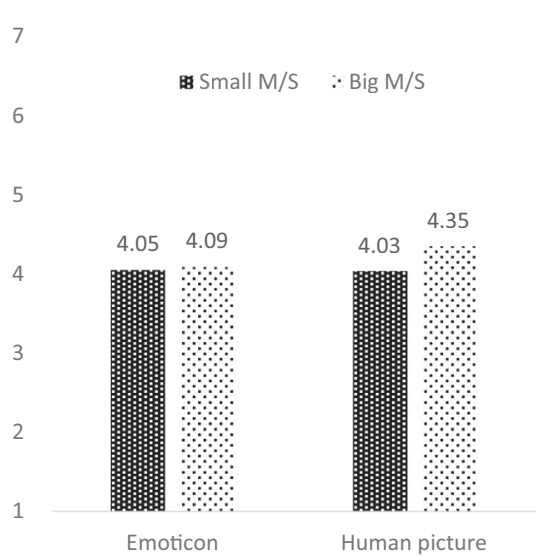

[2. Human agent condition]

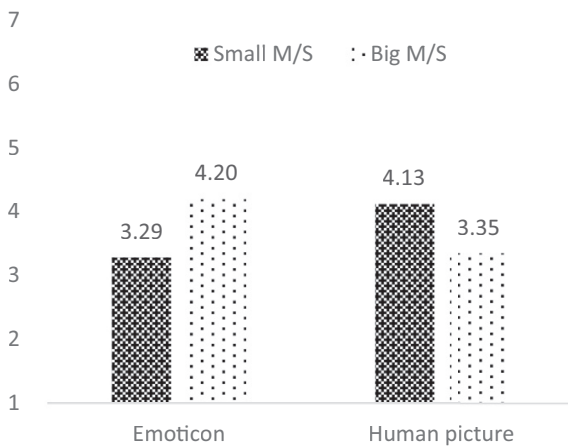

A

[2. Human agent condition]

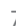

g8 Small M/S $\because B i g ~ M / S$

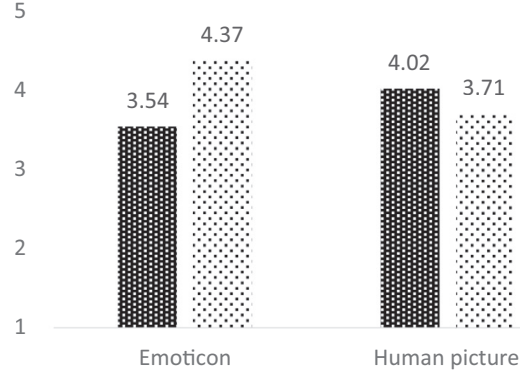

B

Fig. 3. A. Perceived service quality (study 2). B. Customer satisfaction (study 2).

with a human agent online, they perceived greater satisfaction when the agent was presented by a human image rather than a human picture. However, this was true only for high status companies, not for low status companies. Furthermore, when the chatting agent was AI-controlled, this pattern was no longer found. In addition, the results of the mediation analyses indicate that in the case of a high status company, a human agent presented by a human image is perceived to have greater levels of competence, resulting in greater trustworthy and thereby greater customer satisfaction. Taken together, these findings confirmed the role of avatar presentation, company status, and agent identity as we hypothesized.

\section{General discussion and future research}

Online chatting services are everywhere and the use of both human and AI agents is increasing in virtual market places. Because of their operational efficiencies, not only large interrogational cooperation's but also small startups utilize this technological advancement in their businesses. However, sometimes companies have to deliver bad news that will disappoint their customers. In these various service failure situations, will the use of an avatar with only one fixed presentation (i.e., a human picture, human image, etc.) be the best strategy for companies? The current research suggests that companies need to use multiple presentations of their online agents, differentiating the appearance of the online chatting avatars depending on the characteristics of companies and agents.

Our findings from two studies demonstrate that it would be better for high status companies to use human images rather than human-pictures in their avatar presentations, especially when real human agents (not AI agents) control the avatars. Moreover, the mediation analyses show that when a high- 
status company presents a human image avatar controlled by a human agent, it positively affects customers' perceived competence, resulting in greater trustworthiness and subsequently higher customer satisfaction. However, for low status companies, the difference between the two avatar presentation types is not significant. Taken together, these findings indicate that, in service failure context, high status companies, should use a human image avatar controlled by a human agent because it might be seen more competent and trustworthy. By investigating the role of company status, avatar presentation, and agent identity, we contribute to the literature concerning CMC. Importantly, our results show that a more anthropomorphized avatar, presented with a human picture in our study settings, may not be a better choice in service failure context; this provides a boundary condition to the well-known fact that customers feel better and respond more positively to a human-like avatar.

These findings provide a meaningful implication to the uncanny valley hypothesis (Mori 1970). The uncanny valley hypothesis suggests that there is a general trend for humans to like things that demonstrate human features, however, only up to a certain point. If a feature is too human-like, but not yet human, people rather perceive it creepy and unsettling (Nowak and Fox 2018). Our results contribute to this stream of research by demonstrating the specific condition of the uncanny valley hypothesis such that customers are more dissatisfied when rejecting by a more human-like avatar. Considering that more advanced technologies will enable companies to deploy more human-like bots in customer service, our finding will be a useful guideline.

Managerially, our findings also provide meaningful insights. First, companies would be better off designing their avatar presentations that reflect the effect of their market status and agent identity. This might seem to suggest high status companies use human image avatars rather than showing real human pictures for human agents, but we want to be careful on this point. We rather suggest that the decision on avatar presentation be based on the nature of services the agents provide. If the nature of service unavoidably incurs customer complaints (e.g., an insurance claim service having a high rate of denial or a return service with strict limitations), using a human image than a human picture would generate relatively better customer responses as demonstrated in the results of our research, where customers experience a service failure. However, if the nature of a service usually generates satisfying experiences for customers, then the effect of avatar presentation may be different from our results. This would be a good venue for future research also.

Interestingly, study 2 showed that the AI agent condition did not generate a significant interaction between avatar presentation and company status. We suspect this insignificant result may be due to the customer's lack of experiences with an AI chatbot. Although they are becoming increasingly ubiquitous in virtual marketplaces, AI chatbots are still in an early stage and customers' expectations of chatbot services are not as high as ones provided by human agents. Many customers recognize that AI chatbot service has only recently been adopted and is still an evolving area in online marketing communication. Therefore, the results of this study might be different if examining after the chatbot service has been firmly established. It would be a great venue for future research.

In addition, we examined the interplay of avatar presentation, company status, and agent identity in the context of service failure. Thus, it would also be beneficial for marketing researchers to investigate this framework in the context of positive service outcomes. Due to the different nature of gains and losses, we expect that the results from a service encounter involving positive outcomes should be different from our study. In addition, in our two experiments, we utilized human images and human pictures to represent varying degrees of anthropomorphism. However, it would be more beneficial to make variations in a more diverse way by including more variations of human-like avatars. Thus, future research would be better to examine our theorization in different avatar presentation. Meanwhile, in proposing the interaction effect between avatar presentation and company status, relying on the prior literature, we theorize that customers would have greater expectation of a company and this greater expectation would rather backfire if the company with high market-share fails to meet customers' high pre-expectation of online chatting service. However, in the two studies, we did not directly measure customers' pre-expectations. This should be certainly considered in future studies in order to show the logical flow clearly.

Moreover, in study 2, the two-way interaction between avatar presentation and company status 
was found only in the human agent condition, not in the AI condition. Since we did not measure how participants perceived the conversation partner (i.e., either a human agent or an AI chatbot), we cannot conclude that the two-way interaction found in study 1 was based on which type of agent. However, this finding suggests that the joint effect of avatar presentation and agent identity incurs different responses from customers. It would be beneficial for future research to clarify this issue. In addition, in our theorizing we suggest that companies with high market-status would be more likely to have more satisfactory online chatting service to their customers. However, there could be exceptional cases especially when it comes to chatbot service; for example, tech companies could possess better capabilities in online chatting service regardless of their market-status. Therefore, this potential should be considered when interpreting our results.

Lastly, while our paper contributes to the recent literature shedding light on the influence of technological advances such as chatbots or AI on consumers, still many more studies will be required in order to understand the rapid changes of consumer behaviors in virtual service environments. For one, as many companies implement $\mathrm{AI}$ agents in online chatting services, making a consumer's chance of having a conversation with a human agent less popular. However, will consumers be ready to adopt this change? If not, how will they respond? Which type of services would be better served by an AI agent or by a human agent? These issues will be crucial for companies to understand and still are waiting for future research.

\section{Funding}

This work was supported by the 2019 Research Fund of the University of Seoul.

\section{Appendix. Stimuli in Studies 1 and 2}

\section{$<1$. Human image $>$}

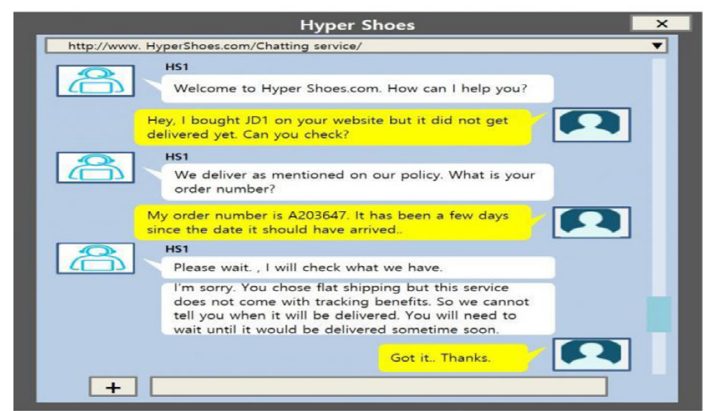

\section{$<2$. Human picture $>$}

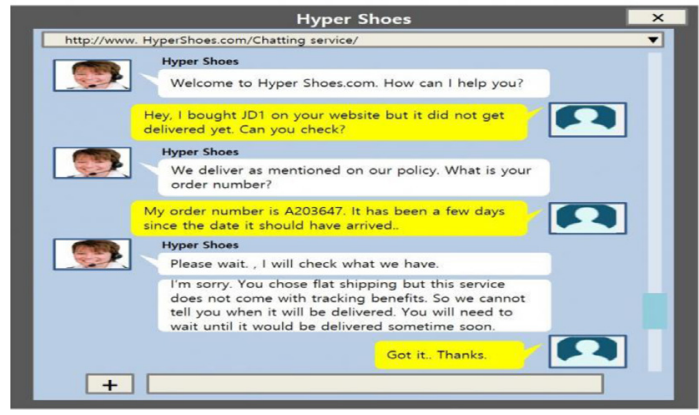

\section{References}

Aguirre-Rodriguez, Alexandra, Adriana M. Bóveda-Lambie, and Paul W. Miniard (2015), "The impact of consumer avatars in internet retailing on self-congruity with brands," Marketing Letters, 26 (4), 631-41.

Araujo, Theo (2018), "Living up to the chatbot hype: The influence of anthropomorphic design cues and communicative agency framing on conversational agent and company perceptions," Computers in Human Behavior, 85, 183-9.

Arm Treasure Data (2019), AI vs. Human customer service, When Do Consumers Prefer a Bot? https://blog.treasuredata.com/ blog/2019/10/08/ai-vs-human/

Bahorsky, Russ, Jeffrey Graber, and Steve Mason (1998), Official Internet dictionary: A comprehensive reference for professionals. Government Institutes.

Bailenson, Jeremy N., Jim Blascovich, Andrew C. Beall, and Jack M. Loomis (2003), "Interpersonal distance in immersive virtual environments," Personality and Social Psychology Bulletin, 29 (7), 819-33.

Bailenson, Jeremy N., Swinth Kim, Crystal Hoyt, Susan Persky, Alex Dimov, and Jim Blascovich (2005), "The independent and interactive effects of embodied-agent appearance and behavior on self-report, cognitive, and behavioral markers of copresence in immersive virtual environments," Presence: Teleoperators \& Virtual Environments, 14 (4), 379-93.

Bailenson, Jeremy N., Nick Yee, Dan Merget, and Ralph Schroeder (2006), "The effect of behavioral realism and form realism of real-time avatar faces on verbal disclosure, nonverbal disclosure, emotion recognition, and copresence in dyadic interaction," Presence: Teleoperators and Virtual Environments, 15 (4), 359-72.

Blascovich, Jim, Jack Loomis, Andrew C. Beall, Kimberly R. Swinth, Crystal L. Hoyt, and Jeremy N. Bailenson (2002), "Immersive virtual environment technology as a methodological tool for social psychology," Psychological Inquiry, 13 (2), 103-24.

Brady, Michael K. and J. Joseph Cronin Jr. (2001), "Some new thoughts on conceptualizing perceived service quality: A hierarchical approach," Journal of Marketing, 65 (3), 34-49.

Caminal, Ramon and Xavier Vives (1996), "Why market shares matter: An information-based theory," The RAND Journal of Economics, 221-39.

Choi, Sungwoo, Stephanie Q. Liu, and Anna S. Mattila (2019), "How may I help you?" Says A robot: Examining language styles in the service encounter," International Journal of Hospitality Management, 82, 32-8.

DeWester, David, Fiona Fui-Hoon Nah, Sarah Gervais, and Keng Siau (2009), "An examination of perceptions of male and female avatars," MG 2009 Proceedings, 5.

Fox, Jesse, Sun Joo Ahn, Joris H. Janssen, Yeykelis Leo, Kathryn Y. Segovia, and Jeremy N. Bailenso (2015), "Avatars versus agents: A meta-analysis quantifying the effect 
of agency on social influence," Human-Computer Interaction, 30 (5), 401-32.

Gong, Li (2008), "The boundary of racial prejudice: Comparing preferences for computer-synthesized white, black, and robot characters," Computers in Human Behavior, 24 (5), 2074-93.

Hamilton, Mark A. and Kristine L. Nowak (2010), "Advancing a model of avatar evaluation and selection," PsychNology Journal, 8 (1).

Han, Sang-Lin, Kyung Sik Jung, Myoung Soung Lee, and Jong Won Lee (2015), "Priority factors of service recovery strategy in distribution channel," Asia Marketing Journal, 17 (2), 97-125.

Han, Haejoo, Sujin Park, and Kyoungmi Lee (2021), "Does political orientation affect the evaluation of artificial intelligence?" Asia Marketing Journal, 23 (2). Article 3.

Hayes, Andrew F. (2017), Introduction to Mediation, Moderation, and Conditional Process Analysis. New York: Guilford Press.

Hellofs, Linda L. and Robert Jacobson (1999), "Market share and customers' perceptions of quality: When can firms grow their way to higher versus lower quality?" Journal of Marketing, 63 (1), 16-25.

Holzwarth, Martin, Chris Janiszewski, and Marcus M. Neumann (2006), "The influence of avatars on online consumer shopping behavior," Journal of Marketing, 70 (4), 19-36.

Kang, Sin-Hwa and James H. Watt (2013), "The impact of avatar realism and anonymity on effective communication via mobile devices," Computers in Human Behavior, 29 (3), 1169-81.

Keeling, Kathleen, Peter McGoldrick, and Susan Beatty (2010), "Avatars as salespeople: Communication style, trust, and intentions," Journal of Business Research, 63 (8), 793-800.

Kim, Seo Young and Youjae Yi (2016), "Give a man a fish or teach him to fish," Asia Marketing Journal, 18 (2), 1-23.

Lee, Jong-Eun R. and Sung Gwan Park (2011), ““Whose second life is this?" How avatar-based racial cues shape ethno-racial minorities' perception of virtual worlds," Cyberpsychology, Behavior, and Social Networking, 14 (11), 637-42.

Mandryk, Regan L., Kori M. Inkpen, and Thomas W. Calvert (2006), "Using psychophysiological techniques to measure user experience with entertainment technologies," Behaviour \& Information Technology, 25 (2), 141-58.

Marinova, Detelina, Ko de Ruyter, Ming-Hui Huang, Matthew L. Meuter, and Goutam Challagalla (2017), "Getting smart: Learning from technology-empowered frontline interactions," Journal of Service Research, 20 (1), 29-42.

Maxham III, James G. and Richard G. Netemeyer (2002), "A longitudinal study of complaining customers' evaluations of multiple service failures and recovery efforts," Journal of Marketing, 66 (4), 57-71.

McGloin, Rory, Kristine L. Nowak, and James Watt (2014), "Avatars and expectations: Influencing perceptions of trustworthiness in an online consumer setting," PsychNology Journal, 12.

McGoldrick, Peter J., Kathleen A. Keeling, and Susan F. Beatty (2008), "A typology of roles for avatars in online retailing," Journal of Marketing Management, 24 (3-4), 433-61.

Moon, Youngme (2000), "Intimate exchanges: Using computers to elicit self-disclosure from consumers," Journal of Consumer Research, 26 (4), 323-39.

Moon, Jang Ho, Eunice Kim, Sejung Marina Choi, and Yongjun Sung (2013), "Keep the social in social media: The role of social interaction in avatar-based virtual shopping," Journal of Interactive Advertising, 13 (1), 14-26.

Moon, Youngme (2003), "Don't blame the computer: When selfdisclosure moderates the self-serving bias," Journal of Consumer Psychology, 13 (1-2), 125-37.
Mori, Masahiro (1970), "Bukimi No Tani [The Uncanny Valley]," Energy, 7, 33-5.

Nowak, Kristine L. (2004), "The influence of anthropomorphism and agency on social judgment in virtual environments," Journal of Computer-Mediated Communication, 9 (2), JCMC925.

Nowak, Kristine L. and Jesse Fox (2018), "Avatars and computermediated communication: A review of the definitions, uses, and effects of digital representations," Review of Communication Research, 6, 30-53.

Nowak, Kristine L. and Frank Biocca (2003), "The effect of the agency and anthropomorphism on users' sense of telepresence, copresence, and social presence in virtual environments," Presence: Teleoperators \& Virtual Environments, 12 (5), 481-94.

Nowak, Kristine L., Mark A. Hamilton, and Chelsea C. Hammond (2009), "The effect of image features on judgments of homophily, credibility, and intention to use as avatars in future interactions," Media Psychology, 12 (1), 50-76.

Nowak, Kristine L. and Christian Rauh (2005), "The influence of the avatar on online perceptions of anthropomorphism, androgyny, credibility, homophily, and attraction," Journal of Computer-Mediated Communication, 11 (1), 153-78.

Nowak, Kristine L. (2015), "Examining perception and identification in avatar-mediated interaction," The handbook of the psychology of communication technology, 89-114.

Press, Gil (2019), AI stats news: $86 \%$ of consumers prefer humans to chatbots, Forbes. Accessed via https://www.forbes.com/ sites/gilpress/2019/10/02/ai-stats-news-86-of-consumersprefer-to-interact-with-a-human-agent-rather-than-achatbot $/$ sh $=31 \mathrm{~d} 2946 \mathrm{~d} 2 \mathrm{~d} 3 \mathrm{~b}$.

Sharma, Abhinav, Sangwon Park, and Juan L. Nicolau (2020), "Testing loss aversion and diminishing sensitivity in review sentiment," Tourism Management, (77), 104020.

Sheehan, James J. and Morton Sosna eds. (1991), The boundares of humaity: Humans, animals, machines. Univ of California Press.

Suh, Kil-Soo, Hongki Kim, and Eung Kyo Suh (2011), "What if your avatar looks like you? Dual-congruity perspectives for avatar use," MIS Quarterly, 711-29.

Swinth, Kimberly R. and Jim Blascovic. (2002), "Perceiving and responding to others: Human-human and HumanComputer social interaction in collaborative virtual environments," in Proceedings of the 5th annual international workshop on PRESENCE, Vol. 392.

Triberti, Stefano, Ilaria Durosini, Filippo Aschieri, Daniela Villani, and Giuseppe Riva (2017), "Changing avatars, changing selves? The influence of social and contextual expectations on digital rendition of identity," Cyberpsychology, Behavior, and Social Networking, 20 (8), 501-7.

Wang, Weiquan, Lingyun Qiu, Dongmin Kim, and Izak Benbasat (2016), "Effects of rational and social appeals of online recommendation agents on cognition-and affect-based trust," Decision Support Systems, 86, 48-60.

Weibel, David, Bartholomäus Wissmath, Stephan Habegger, Yves Steiner, and Rudolf Groner (2008), "Playing online games against computer-vs. Human-controlled opponents: Effects on presence, flow, and enjoyment," Computers in Human Behavior, 24 (5), 2274-91.

Wheeless, Lawrence R. and Janis Grotz (1977), "The measurement of trust and its relationship to self-disclosure," Human Communication Research, 3 (3), 250-7.

Wood, Natalie T., Michael R. Solomon, and Basil G. Englis (2005), "Personalisation of online avatars: Is the messenger as important as the message?" International Journal of Internet Marketing and Advertising, 2 (1-2), 143-61. 